\title{
Index of the Geographical and Ethnic Names
}

A

Alan

Alano-Bulgarian

Altay, Altay Region 13, 25, 33, 43, 50

Aral Lake

Arkadia

Asia (Asia, Central Asia, Middle-West

Asia,

Central and West Asia, Central and

Middle Asia)13, 17, 19, 20, 22, 24, 29 , 33-35,

37-40, 42-44, 46, 52, 64, 65-67, 69

Askania Nova, Chaplynka Raion, Kher-

son District

Astrakhan Steppes

Azov

Azov Steppes

Azov Upland

$19,50,52$

B

Baba, babas $19,34,35,39,55,109$, 118,120 ,

$121,125,161,162$,

Balbal, blbl 29, 30, 35, 36, 39, 43, 44

Balts

Bashkir

Bessarabia

Biliar

Black Klobuk (Chorni Klobuky) 56

Black Sea

$50,51,66,75$

49,51

(Priazov)
Black Sea Plain

52

Black Sea Steppes 11, 20, 29, 35, 39,

42, 46, 49, 50, 54, 169

Bulgarians

28

Bulgaria (Bulgaria, Kama Bulgaria,

the Old Great Bulgaria) $\quad 32,168$

Byzantium

27,67

C

Catacomb culture

35

Caucasus, Northern Caucasus 49, 53 , $66,70,169$

Ciscaucasus, Ciscaucasia 22, 49 , 50-52, 65-67, 161

Cracow

$9-11,15,24,25$

Crimea $19,50-53,57,66,161$

China, Chinese 31-33, 36, 43

Chuvash 30

Czech Republik

$15,160,168$

D

Danube River $49,52,53$

Dikie Pola (Wild Fields) 161

Dmitrievskoye cemetery 32

Dnieper River $49-51,53,56,57,65$, 66, 161

Dnieper River Basin 50-52, 161

Dnieperopetrovsk 21

Dniester River 53

Don River 22, 27, 47, 49-52, 66, 161

Don River Basin (Podonyie) 19, 51 
Donets Seversky River 19, 27, 32, 39, 47, 49-51, 53,

$65,66,68$

Donets Seversky River Basin

Donetsk 9-11, 15, 21, 22, 51, 52, 55 , $66,73,74,76,79,120$

Donetsk Upland

Druzhnoye, Volnovakha Raion,

Donetsk District

\section{E}

Europe, Central Europe, European $13,14,17,19,20,21,22,24$, $27-30,32,34,38,49,52,66,67,69$, $74,76,116,160,166-169$

Eastern Europe, South-Eastern Europe $9,11,13,14,17,23,29,39,50$, $52-55,69,70,113-115,160,161$, $163,167-169$

Europe - Western Europe20, 24, 160, 166,169

\section{F}

First Khaganate of the Turks

G

German

Golden Horde

\section{H}

Helsinki

Hungary

I

Inhul River Inhulets River Irtysh River, Irtysh River Basin Islam $42,48,65,68,69$,

\section{J}

Jergeni Upland

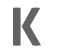

Kama Bulgaria
36,37

18,24 17,56 20 168

18,56 $50,51,57$ 28

69,

Kalmykia, Republic of Kalmykia 57 Kashlagach River 73-75 Kazakh 30, 37 Kazakhstan, West Kazakhstan 37, 38, 64, Kemi Oba culture $\quad 35$ Khakaz 29 Khangai Mountains 31 Kharkiv 19,53, Khazar, Khaganate of the Khazars 32, 37

Khomutovsky Steppe 9,55

Khortytsia 18

Kiev $\quad 10,19,25,53,54$

Kimaks 28, 29, 38, 65, 68

Kimmerians $\quad 35,54,69,167$

Kipchak, Kipchaks 20, 27, 28, 29, 35 ,

$38,39,45,50$,

54,68

Kirghiz, Yenisey Kirghiz 29

Komans 27

Krasnodar, Krasnodar Krai District 52 Kuban River 50, 51, 57, Kuma River 51,57 Kuman, Kumans $\quad 17,27,28,34,50$ Kumania 50,51,52 Kuns 27

Low-Mikhailovsk culture $\quad 35$

Luhansk, Luhansk District 21-23, 52, 53

Lukomorye $\quad 51,66$

Lithuanie $\quad 169$

M

Manych River 22,51,57

Mariupol $\quad 75$

Mayak 32

Mayaki, Slovyanskyi Raion, Donetsk

District 10

Minusinsk Hollow 33

Mius River 51, 53

Mokraya Volnovakha River $\quad 75$

Mokryie Yaly River $\quad 75$

Molochna River 51 


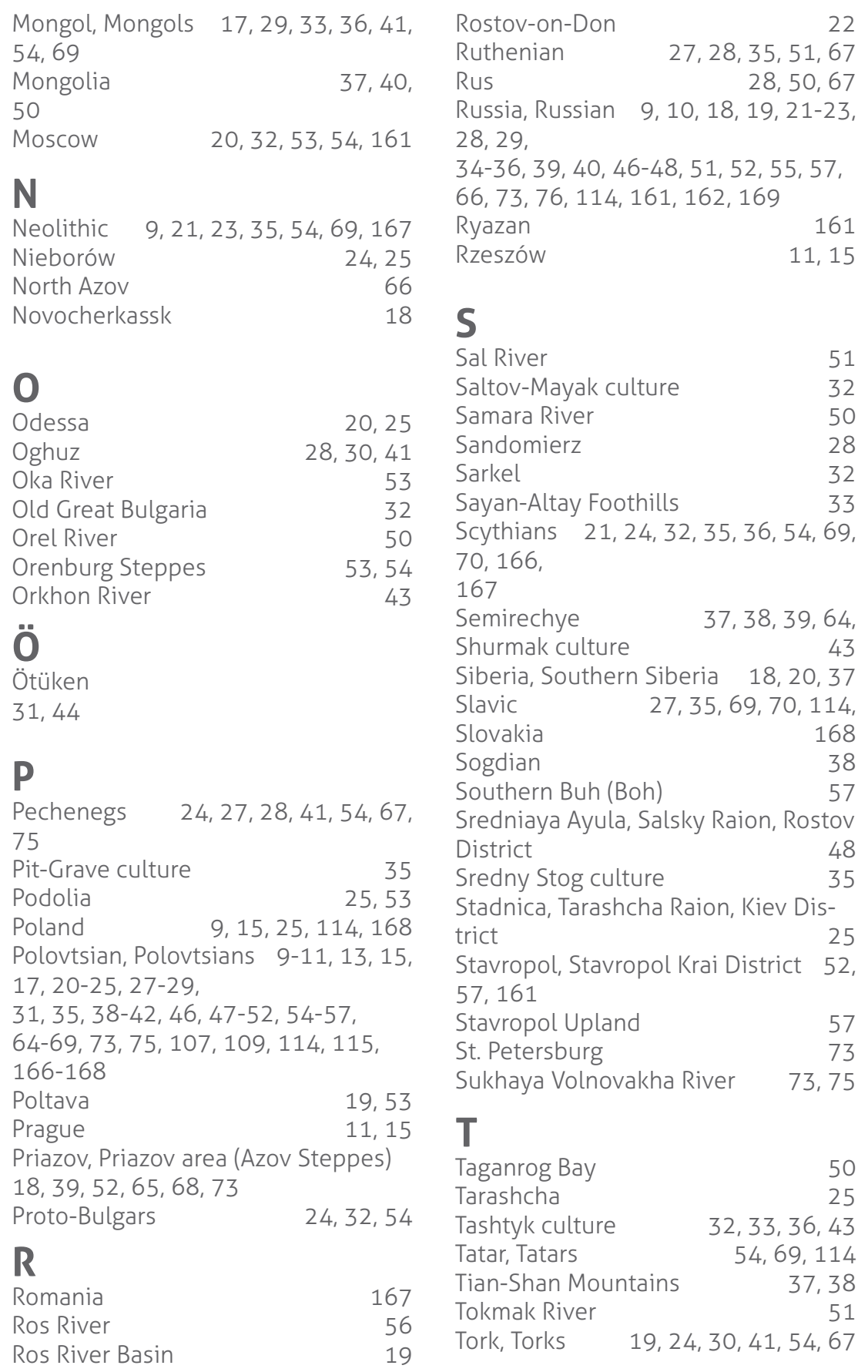


Transvolga (Zavolzhye) 28, 38, 39, 50, 54,68

Tschernikhov

Tsymlyansk gorodishche

Turk, Turks, Turkic peoples, Turkic

tribes $13,19,20,24,27,29-48,51$, 53,

$54,63,67-69,161,168$,

Turkey

Turkmen

Tuvan

U

Ugric

Ukraine $9,10,15,21-25,52,53,55$, 74,76

$84,121,123,159,160,163,169$

Ural Mountains

Uighur, Uighurs, Khaganate of the

Uighur

$29,36,37,38$

V

Verkhny Saltov

Veliko-Anadol, Volnovakha Raion,
Donetsk District10, 14, 15, 70, 73, 75, 76,109 ,

53, $54 \quad 116,119,152,160,163$

32 Venetian 54

Volnovakha, Volnovakha Raion 10, 73-76

Volga River 22, 28, 29, 37, 49, 50-52

Volga River Basin (Povolzhye) 20, 53, 65,67

Volga Region $\quad 27,50,51,161,162$

W

West Khaganate of the Turks 38

Wild Fields 161

Y

Yakut

30

Z

Zaporozhye $\quad 50$ 